\title{
¿Dentro o Fuera de la Universidad? Experiencias de educación superior alternativa: un diálogo entre Boaventura de Sousa Santos y Luis Fernando Cuji Llugna
}

\author{
Boaventura de Sousa Santos' \\ Luis Fernando Cuji Llugna" \\ 'Universidad de Coimbra, Coimbra - Portugal \\ "Universidad Tres de Febrero, Caseros/Bs. As. - Argentina
}

Tristán McCowan (moderador): Agradecemos mucho su colaboración en este proyecto. Vamos a comenzar abordando la situación actual de la educación superior internacional, que ha pasado por un periodo, en los últimos 30 años, de extraordinario crecimiento. Ahora, más de un tercio de la población de jóvenes en el mundo va a algún tipo de educación terciaria, y esta tasa crece muy rápidamente. La institución de educación superior de origen europeo - la universidad - tiene 900 años de vida, parece una institución muy fuerte, con una continuidad muy marcada. Entonces, ¿por qué hace falta cambiar, reformar? ¿Por qué buscar alternativas a este modelo de educación superior convencional, tradicional? Paso la palabra, primero, a Luis Fernando.

Luis Fernando: Gracias, Tristán. Muchas gracias al profesor Boaventura por esta oportunidad. Yo he tenido el gusto de poder comparar las reflexiones de Boaventura con las acciones de un conjunto de iniciativas que se ejecutan para mostrar alternativas de educación superior, que no están desconectadas de alternativas de sociedad, de perspectivas de ver el mundo y de ver la sociedad. En ese proceso, resultan muy estimulantes 
¿Dentro o Fuera de la Universidad?

las reflexiones del profesor y pienso que hay al menos cuatro cosas que entender. La primera, la reflexión sobre los agentes que participan de esta interacción, que no son solamente individuales, sino también colectivos. La segunda, la cuestión de los conocimientos que interactúan, que ya no son solo los conocimientos legitimados desde un lugar, sino otros conocimientos subalternos. Luego, las institucionalidades que se generan y se van modificando en la educación superior convencional. Y, por último, los fines de estas alternativas de educación superior, que van modificándose en el proceso. Entonces, a mí me encantaría conversar con el profesor Boaventura sobre, primero, esta clasificación: ver a la educación superior desde esta forma de clasificar las experiencias, que podría ayudarnos a pensar por qué las sociedades, los miembros de la sociedad, tanto académicos como no académicos, se plantean la necesidad de cambiar, de no sostener o de generar matices en la educación superior que, tradicionalmente, entendemos como convencional.

Boaventura: Muy bien, Luis Fernando, muchas gracias por la referencia a mi trabajo. Yo diría que los cuatro temas cumplen, básicamente, con todo lo que deberíamos reflexionar sobre la educación superior, hoy. Me gustaría, sobre todo, comentar acerca del contexto en el que lo hacemos ahora, porque estos temas son exhaustivos. Si miramos el período que precedió a la pandemia, había dos movimientos impactando la universidad y exigiendo cambios que, además eran contradictorios. Diría que había un movimiento de arriba abajo, que tenía dos fases. Por un lado, la fase del capitalismo universitario, o sea, someter la educación pública o privada a una lógica mercantil, capitalista, de producción de diplomas, proletarización de los profesores, uniformización de los cursos - para que, eventualmente, pudieran ser comercializados a nivel mundial como servicios educativos. Es decir que la propia gestión de la universidad se orientaba por objetivos de productividad capitalista, lo que se empata, en algunos países, con un subfinanciamiento, una crisis de recortes sistemáticos a la universidad pública, en favor de la universidad privada. Por otro lado, un segundo eje de este movimiento de arriba abajo en algunos países, como en los casos de Brasil y de la India es la presión de un conservadurismo, a veces religioso, a veces político, conservador-secular, que tiene diferentes matices; un movimiento que también noto en los Estados Unidos, ya que estoy afiliado, hace 35 años, a la Universidad Wisconsin-Madison, y he vivido, durante estos 35 años, mitad del año en Estados Unidos, y he experimentado también ahí esa presión.

En Brasil se da un conservadurismo evangélico, por ejemplo, que ha creado un movimiento muy fuerte, un movimiento llamado 'escuela sin partido', que, de hecho, es una escuela altamente ideológica, una crítica a las ideologías de izquierda en las universidades - que, ahora, con Bolsonaro, llaman marxismo cultural, una designación que utilizaban los nazis para demonizar a la intelectualidad judía que estaba en las universidades. Entonces, existían estos dos movimientos, pero también existía otro movimiento, contradictorio, desde abajo, que era la presión de los estudiantes, principalmente, ya sea para descolonizar la universidad, por acciones afirmativas, para cambiar los currículos, 
permitir el acceso a las clases populares, a la diversidad indígena. O sea, dos movimientos contradictorios que estaban moviendo la universidad y a los que se tenían respuestas distintas en los diferentes países. Y esto fue antes de la pandemia.

Ahora me parece que las cosas cambiaron y van a cambiar bastante. Yo acabo de escribir un libro, Luis Fernando - que espero que esté disponible en Ecuador, porque fue publicado en España, por Akal - que se llama El futuro comienza ahora: De la pandemia a la utopía. Ahí defiendo que la pandemia se va a quedar con nosotros. La fase aguda va a terminar con las vacunas, pero vamos a entrar en un periodo de pandemia intermitente, con nuevas variantes, nuevos virus, porque el modelo de desarrollo que tenemos es un modelo que conduce a que haya más desestabilización en los hábitats de los animales salvajes, que a veces nos pasan los virus a los humanos y los humanos no tenemos inmunidad. Entonces, me parece que vamos a entrar en un periodo que va a ser más peligroso. ¿Cuál fue el primer impacto de la pandemia? El primer impacto fue en la salud. Ustedes tienen una experiencia fatal en el Ecuador $-\mathrm{y}$ le quiero presentar mis condolencias personales a todos mis amigos ecuatorianos y a Luis Fernando - porque hubo muchas muertes en todos los países, pero Ecuador fue muy martirizado por las muertes de la pandemia. Ahora, me parece que el impacto va de la salud para la escuela, en general, y para la educación, en especial, y para la educación superior. Uno de los impactos de esto es la enseñanza a distancia, en línea, por internet, que es lo que hoy en día, básicamente, sostiene a las universidades de muchos países. Aquí en Portugal, por ejemplo, la universidad sigue cerrada y si bien estamos intentando desconfinar, gran parte de las cosas se hacen por internet, lo mismo ha pasado en Inglaterra y en muchos países. Entonces, me parece que este es un cambio porque lo que veo es que algunos de los movimientos cambiaron bastante.

Por ejemplo, el movimiento estudiantil que era muy fuerte en las universidades europeas; Inglaterra es un buen ejemplo. Hace poco estuve discutiendo esto con la Universidad de Cambridge, para una gran revista de educación que tienen en Cambridge, y la idea era que -yo había estado en Glasgow y en Bristol- parecía que el movimiento para descolonizar la universidad había desaparecido un poco, que estaba suspendido, porque los estudiantes estaban en sus países, en casa, entonces no hay movilidad, no hay presencia en la universidad. Ahora el movimiento del capitalismo universitario está fuerte. Por un lado, hay empresas -yo lo veo bastante en los Estados Unidos- que están pensando que esto es una gran oportunidad para cambiar la educación superior, porque se demostró la capacidad de estas plataformas para dictar cursos en línea y que, obviamente, es mucho más barato. Y es mucho más eficaz, por ejemplo, para evitar la protesta: los estudiantes no pueden protestar si están en su casa. Por otro lado, una universidad donde el gran porcentaje de los profesores tienen contratos precarios, o sea, pueden estar contratados por uno, dos, tres años. Entonces, por ejemplo, si el profesor organiza un curso y este es transmitido en línea, la universidad se que- 
¿Dentro o Fuera de la Universidad?

da con la propiedad del curso y puede seguir ofreciéndolo incluso si el profesor ya no está. Y esto, me parece, hace todo mucho más fácil.

Claro que será un periodo más lento porque recién empezamos; un periodo donde no hay contestación, pero la va a haber. Por ejemplo, con el pago de las inscripciones en la universidad la gente empieza a organizarse para decir 'no podemos pagar tanto a una universidad, donde todo está en línea'. Esto me parece una movida que nos lleva a una primera reflexión que me gustaría tener contigo, Luis: en esta condición de hoy, estamos en una situación que tenemos que criticar y buscar alternativas a la educación superior y, al mismo tiempo, defenderla, porque también hay gente que quiere deshacer la educación. Pienso que el capitalismo universitario y el conservadurismo religioso laico lo que quieren es acabar con las instituciones donde se produce conocimiento libre, plural, crítico, independiente. Idealmente eso sería la universidad. No lo es, lo sabemos, pero debería ser nuestro reto. Entonces, me parece que el reto es, por un lado, producir alternativas y, por otro lado, defender la institucionalidad. No sé qué piensas de eso.

Luis Fernando: Quiero tomar este doble movimiento de modificación de la educación superior en este contexto con el ejemplo, precisamente, de la salud. Este movimiento desde abajo, para el caso de Latinoamérica, que tenía muchos actores colectivos de los pueblos y nacionalidades indígenas, estaba en contra del capitalismo amplio y del capitalismo universitario. Precisamente por la relación de la sociedad, de la universidad, con el medio ambiente. Entonces, este grupo social, este colectivo, que no solo es indígena o afrodescendiente, reivindicaba mantener una relación diferente con la naturaleza y exigía para la universidad recoger ese cambio en la finalidad de la educación superior, no solo la finalidad extractivista, la finalidad de explotación, sino una finalidad que nos permitiera reconciliarnos con la naturaleza para evitar esto que ahora vivimos como efecto de la pandemia, donde los límites con la naturaleza nos han colocado en una indefensión de salud. Y en los movimientos, para el caso de Latinoamérica, se reivindican también esos conocimientos. Es decir, probablemente podamos tener una solución capitalista alrededor de las vacunas para la pandemia, pero también podemos tener una solución integral respecto de la relación que vamos a tener con la sociedad. Los conocimientos que no están mercantilizados nos pueden ayudar. Y si tenemos a la universidad como un espacio de producción y reproducción de esos conocimientos, podemos generar una alternativa para la sociedad y una solución más integral a la pandemia. Creo que esa dimensión de los fines nos debe ayudar a que, en este contexto, no solo percibamos el beneficio que tiene la ampliación en el acceso, por el internet, sino también una reflexión sobre los fines que la universidad debe perseguir.

Boaventura: Estoy totalmente de acuerdo. Pero esta cuestión de las ventajas de la internet también oculta las grandes desigualdades de la sociedad por el acceso. Si vamos a ver los últimos informes de la OCDE sobre educación, debido al impacto de la pandemia, la tele-escuela, es decir, la escuela en línea o la escuela cerrada tiene un impacto devasta- 
dor en África porque gran parte de los niños, no puedo precisar el número, pero pienso que en el Congo, por ejemplo, un $60 \%$ de los niños abandonaron el sistema escolar. Y pienso que en el nivel de la educación superior, este aumento que Tristán ha referido de las clases bajas que entraron en la universidad, pienso que sus viviendas, muchas veces, no tienen las condiciones de silencio, ni conexión, ni las computadoras, etcétera; porque una familia puede tener una computadora, pero no hay una para cada miembro de la familia. Hay aquí desigualdades, pero, estoy de acuerdo contigo, en que deberíamos aprovechar la crisis como una oportunidad. La raíz de la palabra crisis, en griego, es esa, una enfermedad, pero es también una oportunidad y pienso que sí, que deberíamos usarla y ver cómo lo vamos a hacer, ya que el problema es la participación.

Yo no pienso que sea posible imaginar una educación superior a distancia. Acepto que se utiliza bastante la internet en la enseñanza universitaria, pero nunca se va a prescindir de la posición protagónica del profesor, sobre todo, porque no es simplemente la enseñanza, es la convivencia. O sea, la universidad es un sistema de copresencia, de convivencia, de enseñanza de la ciudadanía, donde puedes encontrar compas que tienen una visión distinta de la tuya, de tu grupo étnico, de tu religión, de tu familia, de tu región. Esto es muy importante para crear ciudadanía y eso, me parece, es lo que puede estar en riesgo si no encontramos un modo de volver a las universidades, a los espacios donde los estudiantes puedan socializar. Sobre todo, porque sabemos, por estudios de la sociología de la educación, que es tan importante el currículum y el plan de estudios oficial de la universidad como el llamado currículo informal, que es lo que los estudiantes aprenden unos de los otros, en el espacio universitario y la convivencia. Esta formación tiene un valor enorme; nosotros no eliminamos el currículo oficial para estar en línea, pero eliminamos la parte del currículum informal de enseñanza por convivencia y eso, me parece, que también es un problema.

Luis Fernando: Yo estoy de acuerdo, digamos, en que hay por detrás un gran riesgo que no es hacia el futuro, sino que estamos viviendo una situación de maximización de la exclusión de ciertos grupos por cuestiones de pobreza, por cuestiones de acceso a la tecnología, por cuestiones de distancia y, probablemente, ese riesgo se ve maximizado porque la política estatal o las políticas universitarias eligen solamente una opción. Entonces, estamos en pandemia y todo lo vamos a hacer en línea, cuando, probablemente, en los espacios donde no hay este tipo de acceso pueden florecer iniciativas que, cuidando la bioseguridad que ahora está tan de moda, generen espacios de socialización, incluso por fuera de la estructura más grande, que es más urbanizada, que tiene esta característica de normalización de un estilo de vida, de un tipo de aprendizaje, especialmente para rescatar algunos conocimientos que no se estaban tomando como legítimos para transmitir en las universidades. Me pongo a pensar en nuestro país, en el modo de vida campesino que rescataba el hecho de que tú podías hacer mucho de lo que consumías y que con las medidas de confinamiento produjo que los espacios de 
¿Dentro o Fuera de la Universidad?

educación más rurales pudieran potenciar ese tipo de conocimientos en espacios institucionalizados, como es la escuela, como puede ser la universidad que está más cercana a estos espacios. Estoy totalmente de acuerdo en que si no visibilizamos las exclusiones que hay, no vamos a permitir que los Estados y que las universidades generen, al mismo tiempo, soluciones paralelas, porque la pandemia afecta diferenciadamente a los ciudadanos. ¿Qué experiencias conoce usted, profesor, de este tipo de cosas ahora, justo en la pandemia?

Boaventura: Sí, realmente tiene razón, Luis Fernando, se agravaron. En este libro dedico un capítulo entero a la profundización de las desigualdades sociales porque el virus - yo escribí un librito, que es libre, se llama La cruel pedagogía del virus - nos está enseñando cosas, de una manera cruel porque enseña matando, pero es una enseñanza de la Madre Tierra en el sentido de que no podemos seguir con este modelo de desarrollo, porque la vida humana representa el $0.01 \%$ de la vida total del planeta y, a pesar de eso, nos arrojamos en el llamado Antropoceno para destruir la vida del planeta. Entonces, quizás el planeta no está en riesgo, pero la vida humana en el planeta puede estarlo.

Nuestros hermanos indígenas nos han mostrado el futuro, no el pasado, sino el futuro. Todo lo que está en la constitución del Ecuador, también en la constitución de Bolivia. En Ecuador, de una manera muy impactante, los derechos de la Naturaleza, la Pachamama, la Madre Tierra, son líneas de futuro que podrían defendernos. Pero hay dos puntos: por un lado, estas desigualdades se agravaron muchísimo porque tú notas que, por ejemplo, Brasil, en este momento, es una catástrofe sanitaria porque tiene un presidente que, a mi juicio, es un genocida, porque tiene una política - que algunos piensan que es intencional - de hacer lo que llamamos darwinismo social, o sea, aprovechar la pandemia para liquidar a los pobres y a los negros del país. Llevamos más de trescientas mil muertes y se calcula que hacia fines de 2021 pueden llegar a quinientas mil, medio millón de personas, cuando eran evitables, en un país que podía producir vacunas. Hay aquí una lógica muy dura y se nota que las poblaciones que ya estaban vulnerabilizadas por crisis anteriores (el hambre, el desempleo, el trabajo precario, la violencia de género, la brutalidad policial) son las que han sufrido más con la pandemia. Refugiados, migrantes, etcétera y los pobres, obviamente, la gente empobrecida que vive en asentamientos informales, chabolas, favelas. Por eso, es claro que la crisis profundiza, de una manera brutal, las desigualdades.

El otro fenómeno es este: yo, por ejemplo, desde hace un año estoy en mi pueblo, en el mundo rural, a treinta kilómetros de Coimbra. En el pasado, la gente que se quería defender de las pandemias, ya en el siglo XIV, se refugiaban en el campo, porque el campo es más seguro, es más bioseguro, tiene más posibilidades de autonomía agrícola y otras. Por ejemplo, Boccaccio escribió el Decamerón en un pueblecito; salió de Florencia, porque si se quedaba, moría con sus padres, quienes murieron durante la pandemia, la llamada peste negra. Entonces, vamos al campo para protegernos. Yo aquí en este campo tengo el comercio local 
muy cerca, alimentos saludables. Además, produzco, en unos pequeños terrenos, papas, legumbres varias, etcétera. O sea, nuestro modelo de desarrollo se ha centrado en las ciudades y ha abandonado el campo. Las universidades fueron un gran agente de urbanización, pero ahora estamos en un momento en que hay que desurbanizar, digamos, en el buen sentido, y crear nuevas condiciones que les permita ruralizarse. En ese libro, en la parte de las alternativas, hablo de que deberíamos repensar las relaciones entre ciudad y campo.

El segundo aspecto del que quería hablar es de nuestras televisiones. Todos los días, en varios países, hablan de la ciencia moderna, aplicada, aplicada a la salud. Al menos ahora ya no son los economistas, eran siempre los economistas los que estaban en los noticieros. Ahora son científicos, médicos infectólogos, epidemiólogos, virólogos, etcétera, y eso da la ilusión de que, finalmente, es la Ciencia el único conocimiento válido. Y a mí me preguntan mucho: profesor, ¿ cómo es esto de las epistemologías del sur, de la ecología de saberes? Y no es porque yo sea anticiencia, de ninguna manera, soy un científico social, pero pienso que la ciencia no es el único conocimiento válido, pues hay otros conocimientos también válidos: los conocimientos indígenas, rurales, campesinos, etcétera, eso es lo que hay que traer. Se está dando lo que yo llamo un proceso de sociología de las ausencias, o sea, se está invisibilizando. Cuando en mi trabajo para este libro fui a estudiar lo que estaba pasando con las comunidades indígenas -no tengo información concreta de Ecuador, pero tengo de Colombia, donde trabajo ahora bastante-, por ejemplo, en el sur de Colombia, los pueblos indígenas acabaron por publicar pequeñas recetas de su medicina tradicional porque la medicina tradicional indígena, obviamente, no es buena para enfrentar una crisis aguda porque no tienen vacunas, pero aumenta la inmunidad del cuerpo para enfrentar los efectos más dañinos de la pandemia y la Organización Mundial de la Salud reconoce eso, de alguna manera. Entonces, publicaron estos libritos de promoción de la medicina tradicional para que la gente se defienda. Y no necesitas ni gel, ni alcohol, sino ciertas hierbas que al manejarlas con las manos, desinfectan. Esta diversidad está muy presente, el problema es que no es visible.

Pienso que en algunos países estamos avanzando bastante hacia lo que llamo una ecología de saberes, es decir, traer al interior de la universidad los conocimientos interculturales, populares, etcétera. En Brasil, por ejemplo, hay universidades donde podían recibir a los llamados maestros de saber notorio, o sea, maestros de saber indígena y afrobrasileño que podían hablar con los estudiantes; si era en la facultad de medicina, por ejemplo, traían médicos tradicionales. Todo esto me parece que se perdió por ahora y estoy un poco preocupado porque el potencial está ahí, pero veo que hay un cierto estancamiento de todo este movimiento.

Luis Fernando: De hecho, profesor, yo me pongo a pensar sobre cómo apoyar el crecimiento de esta posibilidad de visibilización de saberes alternativos y ahí entran en juego dos cosas que a mí me parecen muy importantes. La posición de poder que tiene o tenemos los actores del mundo de la educación superior convencional. La voz de un académico 
¿Dentro o Fuera de la Universidad?

con las credenciales legitimadas para pronunciarse lo coloca en una posición de poder respecto de estos saberes alternativos y le posibilita obstaculizar o propiciar que estos saberes ingresen a la universidad. Y ahí me parece que hay tres criterios que están en disputa y donde yo siento a la comunidad académica no totalmente decidida; una disputa interna que es epistemológica, que es política y que es axiológica. Es decir, los criterios de verdad, si los criterios de verdad se ubican, de entrada, en lo que convencionalmente conocemos como ciencia y subvaloramos, de entrada, y excluimos estos conocimientos. Los criterios axiológicos de lo bueno, de qué es bueno, también nos impiden institucionalmente y ahí mi creencia es que no tiene que ver tanto con los Estados, sino con el campo universitario. Y un criterio que puede entenderse como muy capitalista, pero que, en el contexto de la pandemia, queda claro que excede a una sociedad capitalista, que es el criterio de eficacia. Tenemos ahora la disputa sobre la eficacia de las vacunas, pero hay una disputa más grande sobre la eficacia de nuestras soluciones respecto de la problemática de la pandemia. Creo que estos tres criterios, dentro del campo universitario, deben sufrir un cuestionamiento serio para posibilitar que los conocimientos y los poseedores de esos conocimientos ingresen a este campo y me parece que esa no es una disputa tan directa del Estado, sino del campo universitario, de los agentes del sistema. ¿Qué opina usted, profesor?

Boaventura: Luis, tienes toda la razón, me alegra que pongas tan claramente estos tres criterios porque me parece que nos ayuda a manejar la temática. Empezando por el primero, es curioso que estos criterios sean una cosa en la teoría que los ha definido, pero otra cosa cuando son aplicados, sobre todo, por agentes no solamente administrativos, sino también profesores, presidentes, etc., porque hay presiones. Por ejemplo, empecemos con la verdad. Claro que todos nosotros, que desde los ochenta venimos escribiendo en contra del paradigma positivista de la ciencia, sabemos que no hay verdad en la ciencia, sino búsqueda de verdad. La ciencia es una búsqueda constante porque si hubiera verdad en la ciencia, la verdad, una vez definida sería la misma para siempre. Al contrario, lo que es verdadero hoy, mañana no lo es. Entonces, queda claro que lo que fue verdadero entonces, no es verdadero ahora. Hay una búsqueda de verdad que nada tiene que ver con el relativismo, al contrario, es la idea de que de buena fe tú usas los métodos, las metodologías, para poder obtener los mejores resultados. Ahora, esto nos da apertura para entender que puede haber otros criterios de búsqueda de verdad que no son los que nosotros utilizamos, son otros métodos, otras metodologías. En mis experiencias de estar con una comunidad de indígenas, en una selva, me dicen esta planta, esta otra y aquella, ¿y cuál es la metodología? Hay metodologías distintas, o experiencias, o sabidurías, el conocimiento ancestral, procesos y elementos de espiritualidad, de contacto privilegiado con los ancestros. Son cosas muy complejas que no entran, pero que tengo que respetar porque son también una búsqueda de verdad y para ellos tiene eficacia dentro de sus territorios. Lo que pasa hoy es que, con la pandemia, se habla de ciencia aplicada, 
de vacunas, o sea, la ciencia es buena para producir vacunas. La ciencia aplicada, o sea, la tecnología es totalmente distinta de la ciencia básica. Esta última es la que busca y acepta la idea de búsqueda de la verdad porque busca lo inesperado, lo desconocido, y casi nunca se completa, porque sigue siempre. La ciencia aplicada, tecnológica, es la que crea resultados para transformarlos en instrumentos o medicamentos o vacunas. Entonces, el positivismo está regresando con una fuerza enorme. Por ejemplo, aquí, la Unión Europea va a gastar millones de euros en ciencia, pero no es ciencia básica, es aplicada, ciencia-innovación, ciencia al servicio de la industria. Yo no tengo nada en contra de esto, pero no es ciencia básica, es otra cosa. Y esto es lo que crea la asimetría, porque cuando las agencias multilaterales imponen a Ecuador o a Brasil o a Portugal, que deben promover la ciencia aplicada, pero no la ciencia básica, lo que pasa es que aumenta la disparidad entre el norte global y el sur global, porque los países más desarrollados ya hicieron mucha ciencia básica y ahora la aplican. No empezaron con la ciencia aplicada, empezaron con la ciencia básica. Entonces, lo que veo es que los institutos de ciencia pueden buscar financiamiento para, simplemente, hacer innovación, pero lo básico sigue sin aparecer. Esto, por un lado, me parece muy importante.

Por otro lado, en cuanto al criterio de eficacia, que es un criterio de política para la sociedad, pero es también un criterio para la profesión del profesor, del investigador universitario superior. Con este movimiento de productividad capitalista en las universidades los profesores son llevados a publicar lo más posible en revistas que, casi en su totalidad, son en inglés. Entonces tú estás en un país de habla española o portuguesa o china, o lo que sea, pero tienes que publicar en inglés, porque si no, tu carrera, tu desarrollo, no va a tener lugar. Es decir, la responsabilidad social que nosotros como académicos tenemos con nuestras sociedades desaparece un poco, porque estamos hablando en una lengua que la gente ni siquiera entiende. Me parece que sería fundamental, para cambiar incluso dentro de las universidades convencionales, expandir los departamentos de extensión. La extensión universitaria es algo muy específico de América Latina, que viene desde el movimiento de los estudiantes de Córdoba, Argentina, en 1918, de incrementar la responsabilidad social de la universidad con el trabajo con la comunidad, no con el trabajo con las empresas, sino con las comunidades, en general, con la gente, con la ciudad. Eso no se está promoviendo porque los profesores tienen una presión enorme para publicar, sobre todo, en inglés. Y esto repercute después en lo del criterio axiológico porque se estrechan las variables culturales de las cuales se puede encontrar conocimiento eficaz y aplicado. Entonces, el espacio de interculturalidad, que sería importantísimo, se pierde un poco.

Los retos en esto son muy grandes en este momento. Yo veo estudiantes míos, por ejemplo, que hicieron el doctorado aquí en mi centro que ahora son profesores en varias universidades. Ahora mismo tengo dos estudiantes de doctorado de Ecuador, que están trabajando aquí con nosotros; dos de ellos, también ecuatorianos, terminaron su doctorado 
aquí en mi centro, y a veces me dicen que tienen dificultades para poder seguir con la idea de incluir la ciencia en un conjunto más amplio de saberes porque son desestimulados y porque, al mismo tiempo, los estudiantes no están interesados. Porque se creó la idea de que tener un diploma no es para aprender, sino para obtener un empleo. Esto me parece preocupante, pero pienso que tus tres criterios cubren muy bien las cosas.

Tristán: Profesor, gracias. Tomando como base las reflexiones que ustedes han hecho sobre la pandemia y la situación actual de la educación superior, la ciencia, la búsqueda de la verdad, etcétera, pasamos ahora la atención a las experiencias actuales de alternativas, sean de tipo pluriversidad, iniciativas dentro de las universidades convencionales, o universidades interculturales o indígenas, y experiencias al margen de los sistemas, de tipo subversidad. ¿Cómo ven ustedes estas experiencias hoy en día, sus logros hasta ahora y los desafíos que enfrentan?

Luis Fernando: Yo quisiera compartir con el profesor una experiencia y unas reflexiones que me cuestionan sobre esta experiencia. En Ecuador, el movimiento indígena presentó, desde hace muchos años, una alternativa a la universidad que empezó siendo una alternativa no institucional. Pero, por decisión del movimiento, implicaba institucionalizarla en una universidad que tiene el nombre de Universidad Intercultural Amawtay Wasi. Llegó un momento en que esa universidad se cerró por criterios de calidad y, luego, la dinámica de Ecuador posibilitó que se reabriera y se transformara: de una universidad particular y comunitaria pasó a ser una universidad pública y comunitaria. Esto produjo un movimiento y, en consecuencia, los actores que habían iniciado esto, ya no pudieron continuar, porque se solicitaron algunos criterios para su participación en esta iniciativa. Por ejemplo, que se refiriera la obtención de títulos. Entonces, la dinámica de estas iniciativas con la posibilidad del Estado de imponer ciertos criterios puede desvirtuar una parte de sus finalidades.

Ahora tenemos una institución que es intercultural, de los pueblos y nacionalidades, que tiene como autoridades doctores que se autoidentifican como indígenas o afrodescendientes. Sin embargo, los movimientos han perdido algo. Siempre existe la posibilidad de cuestionarse si eso que se pierde es justo lo más necesario de las experiencias y cómo podemos posibilitar una mejor relación, sabiendo que existe esta diferencia de poder entre las iniciativas y la relación del Estado. Hasta allí un poco mi pregunta, compartirle esta experiencia que vivimos en Ecuador que, por lo que conozco, en Latinoamérica hay experiencias similares de la relación del Estado con las iniciativas de los movimientos sociales, movimientos indígenas.

Boaventura: Sí, Luis, me alegra que trajeras este caso porque yo también lo conozco. Hace años estuve muy cerca de la Amawtay Wasi y acompañé un poco todo este proceso, durante el gobierno de Rafael Correa, porque fui a dictar un nuevo seminario, invitado, en ese entonces, por Luis Macas. Y fue muy lindo porque se reunieron bastantes organiza- 
ciones indígenas, jóvenes, que llegaron de varias partes, y volvimos a discutir esta cuestión de las epistemologías del sur, con diferentes personas con diferentes trayectorias. Fue muy interesante, por ejemplo, comparar conceptos de la naturaleza, la naturaleza eurocéntrica cartesiana y la Madre Tierra, los conceptos de espiritualidad, la idea de comunidad e individuos, todo esto que es parte de mi trabajo. Fue un debate muy interesante. Después, la universidad me comunicó el intento del gobierno de reconocerlos, pero siguiendo los parámetros de calidad que pasaban por tener grados académicos que, obviamente, no tenían los líderes indígenas. Incluso, yo escribí al gobierno en defensa de mantener la autonomía de la Amawtay Wasi a través de una u otra articulación con la CONAIE [Confederación de Nacionalidades Indígenas del Ecuador], porque me parecía que someter una universidad intercultural a criterios monoculturales no es válido, por ejemplo, obligando los profesores a tener un doctorado. No es así para los sabios de las comunidades, que pueden ser iletrados, pero tienen una sabiduría ancestral que es absolutamente valiosa para la comunidad, para todos nosotros. Entonces, después de muchos incidentes, se dice que la idea no era cerrar, sino crear una universidad pública comunitaria, lo que en sí mismo es bueno, es un tipo nuevo de universidad, pero los criterios siguieron siendo monoculturales, en gran medida. Además, como era una universidad pública, a pesar de estar en un país que tiene una constitución para un Estado plurinacional, no se quiso que la CONAIE, por ejemplo, pudiera controlar la calidad de la universidad autónomamente. Como tú sabes, en Ecuador, las organizaciones indígenas controlaron, durante mucho tiempo, la educación bilingüe.

Yo fui muy solidario con el gobierno pasado, en muchos aspectos, y fui crítico, en otros; fui crítico con el Yasuní, fui crítico con la educación intercultural y, por esta razón, fui crítico con la Amawtay Wasi. Pienso que se perdió mucho, Luis Fernando, precisamente porque yo sé que la comunidad indígena, las organizaciones, están muy distantes de la Amawtay Wasi ahora, la ven como un cuerpo extraño, digamos, y están en búsqueda de reconstruir sus propios procesos autónomos, pero al margen del Estado.

Entonces, hay que ver otros modelos. En mi experiencia, conozco tres. Uno es el de Amawtay Wasi, como vimos, y hay otros dos: uno son las universidades interculturales, indígenas, por ejemplo, totalmente autónomas del Estado, o que lo fueron durante mucho tiempo y siguen estando dirigidas y administradas autónomamente. Me refiero a la Universidad Intercultural Indígena de Popayán, en Colombia, que surgió como una iniciativa del CRIC [Consejo Regional Indígena del Cauca], que es una de las organizaciones del Cauca indígena, muy fuerte. Ellos fundaron esta universidad, donde yo estuve y participé en algunos seminarios, y lo que pasó fue que crearon ciertos temas que no estaban en las universidades convencionales. Por ejemplo, 'agentes de desarrollo local', jóvenes que podrían estar muy bien preparados para hablar con la gente, con los pueblos, decidir cuáles son sus problemas y demás, que no estaba en el currículo de la universidad. Crearon una carrera que 
¿Dentro o Fuera de la Universidad?

no era reconocida por el Estado. Y, hace un par de años, el gobierno de Colombia, que es un gobierno de derecha, reconoció esta carrera oficialmente. La ministra de educación fue a Popayán a decir: a partir de ahora, los agentes de desarrollo local que están formados por la Universidad Intercultural Indígena son reconocidos por el Estado, por las alcaldías, para sus funciones. Esta es una articulación virtuosa, yo diría, mucho más plurinacional que la de Ecuador, a pesar de que Colombia tiene un gobierno de derecha, que no tiene nada que ver con la plurinacionalidad. Fue muy interesante ver esto.

La otra experiencia que, en este momento es un poco difícil de evaluar por todo lo que pasó en Bolivia, se refiere a las tres universidades interculturales indígenas que Evo decidió crear: una guaraní, una aymara y una quechua. Por lo tanto, las tres grandes lenguas de la Amazonia y de la Sierra, pero con autoridades indígenas que son muy fuertes y en el único país que tiene mayoría indígena. Pero, por supuesto, son reguladas desde el Estado. Allí me parece que hay conflictos, hay problemas, porque el Estado tiene una lógica monocultural. Yo pienso que Ecuador fue un poco lejos, demasiado lejos en esa monoculturalidad. Pero, en general, todos los Estados intentan siempre ver una ley general, universal, que se aplique a todo el país y ahí las diferencias se pierden. Hay otra universidad que es totalmente autónoma, diría que es el cuarto modelo, la Unitierra [Universidad de la Tierra] en Chiapas. Aunque quizá la más importante ahora es la de Oaxaca, cuyo presidente es un gran amigo mío, un gran intelectual comunitario, Gustavo Esteva. Esta universidad no quiere nada con el Estado, allí se enseña el conocimiento campesino, indígena, local, de las emergencias. Entonces, me parece que hay una variedad enorme, y hablamos simplemente de los indígenas.

Tengo dos estudiantes que están terminando tesis sobre las universidades populares, entonces, hay mucha universidad popular, de distintos tipos, hay en Argentina, la escuela Florestan Fernandes, en Brasil. Hay muchísimas otras universidades populares y no solamente en América Latina. En Canadá son muy fuertes, en Estados Unidos, incluso en Europa hay universidades populares, de otra raíz. Como hay también en América Latina algunas universidades populares que vienen, sobre todo, de los partidos comunistas de los años veinte, que crearon esas universidades populares que no tenían nada de interculturalidad, no era nada de ecología de saberes, eran para divulgar el conocimiento científico a los obreros. Los profesores más progresistas, de izquierda, al final de la tarde, iban para los sindicatos locales, iban a los espacios culturales de la comunidad obrera, y ahí enseñaban Ciencia, Biología, Filosofía, etc., porque los obreros no tenían acceso a la universidad. La India también tiene una gran tradición de educación popular, gandhiana y de otros matices; he trabajado con algunas de ellas y son de una riqueza enorme. Entonces, hay un panorama muy vasto. Lo que pienso es que todas estas universidades son presenciales, en gran medida, y pueden usar computadoras, pero la enseñanza no es en línea porque la presencia, la copresencia es fundamental. Por eso no podemos discutir este tema sin ver que hay un elefante en la sala que es el virus, que nos va a impactar a todos en el futuro. 
Luis Fernando: Profesor aquí tengo dos preguntas y espero que no sean tan distantes una de la otra. La primera es esta limitación conceptual que a veces tenemos en nuestro aparataje sobre este pensamiento casi dicotómico entre izquierdas y derechas, o lo subalterno y lo hegemónico. Porque como usted mostró es a veces paradójico que la diversidad de las izquierdas produzca estos espacios de disputas al interior de la izquierda que posibilitan que más bien lo que entendemos más por derecha permita que estas iniciativas se produzcan, se legitimen y empiecen a estar dentro. Esto a mí me cuestiona porque nos cuestiona la unidad en las luchas sociales alrededor de la justicia que tienen estas iniciativas y que a veces encuentran su mayor oponente en el mismo lugar de la izquierda. Y lo segundo, alrededor de lo último que usted manifiesta, tiene que ver con la importancia de las lenguas. Todas las plataformas, todas las iniciativas que se sacan empiezan probablemente por el inglés, logran estar en español, pero esto impacta fuertemente en el tema de los conocimientos por la lengua en la que se expresan, por la lengua que es la que permite operar desde la plataforma del zoom hasta los textos. Estas dos dimensiones pueden afectar sensiblemente el desarrollo de estas iniciativas y su coherencia, me parece.

Boaventura: Estas son grandes cuestiones, por supuesto, Luis Fernando. Y mira, va a ser publicado ahora también en Ecuador, finalmente, un librito que escribí, que está en español, en portugués, pero nunca lo publiqué en inglés, se llama Izquierdas del mundo uníos. Yo tengo la preocupación, como hago las ecologías de saberes y las epistemologías del sur, he visto mucha divergencia - lo vemos en el Foro Social Mundial - entre diferentes conocimientos de mujeres, de indígenas, de campesinos, etcétera. Y por eso fundé la universidad popular de los movimientos sociales, de lo cual no hemos hablado (Alice-ES, 2020). He escrito bastante sobre la universidad popular porque es mi primer intento de pasar la pluriversidad a la subversidad, porque es una universidad popular autónoma, pero con una intención política de transformación, de unidad entre los movimientos sociales, de unidad entre los conocimientos, científico, académico, conocimiento popular. Si vas a la página de la universidad, verás cómo hemos organizado talleres en todo el mundo, más en América Latina, en África y en Mumbai, en la India. No tanto en Europa, allí organizamos solo dos o tres; vamos a organizar más cuando pase la pandemia. Organizaremos uno el próximo año en el País Vasco, en el Estado español. La idea es que un tercio sean académicos, dos tercios sean líderes de diferentes movimientos sociales - no pueden ser los mismos porque queremos interconocimiento entre los movimientos - durante dos días. Y es muy fructuoso porque es un ambiente informal, donde nadie puede hablar más tres minutos, cinco minutos, en cada intervención, donde hay convivencias, se baila, se come, se bebe, en un espacio no universitario. El último que realizamos, de hecho poco antes de la pandemia, fue en Caruaru, en el nordeste de Brasil, en el Centro Cultural Paulo Freire, que es un centro cultural del movimiento de los Sin Tierra y su asentamiento en Caruaru. Fue lindo, dos días de reflexión sobre las luchas populares hoy, y fue presencial, por supuesto. Para mí, la experiencia que tengo de la subversidad es esta. 
¿Dentro o Fuera de la Universidad?

Eso me llevó después a pensar que lo que intentamos hacer en la universidad popular con los movimientos sociales, podríamos hacerlo también con los partidos de izquierda. Y busqué cómo sería posible vencer el dogmatismo, el sectarismo, la monoculturalidad de las izquierdas, con una izquierda intercultural, y ahí lo diferente y mi fracaso total porque es realmente muy difícil penetrar en esto. Vamos a ver cómo es recibido el libro en Ecuador. Yo soy adepto de que la distinción izquierdaderecha sigue, obviamente, y de que hay conocimientos hegemónicos y contrahegemónicos, pero hay que reconstruir los conceptos, hay que reconstruir, sobre todo, la parte de las izquierdas cuando la extrema derecha está ganando tanto, y cada vez más, espacio. Pero se ha creado, al mismo tiempo, la idea de que los gobiernos en América Latina, que se llamaron después 'progresistas' - y recuerda, Luis Fernando, que la palabra progresismo fue inventada por algunos intelectuales activistas de izquierda para decir que estos gobiernos no eran de izquierda. Estoy hablando de Evo, estoy hablando de Rafael Correa. Y en algunos lados en América Latina si te llaman progresista es casi como llamarte fascista. Entonces es una subversión total, porque pienso que estamos en una fase donde deberíamos entender qué es lo que ocurre, lo que en mi trabajo llamo la teoría de la transición. Nosotros no podemos pasar de un modelo cartesiano de la naturaleza a un modelo de Pachamama de un día para el otro. Debe haber una transición histórica, de décadas. Eso me parece problemático. Claro que en Colombia la explicación no es tanto por la sensibilidad de los indígenas, es un gobierno que no se quiere comprometer mucho con la protección de los indígenas y decidió dar alguna visibilidad a algo que es bastante secundario, pero fue una actitud buena, que yo apoyé y elogié bastante. La lengua, ese es el problema, Luis Fernando, es lo peor, lo más perjudicial, a mi juicio. Ahora acuñé el término 'epistemicidio', la muerte y destrucción de conocimientos, lo que hacemos, muchas veces, en las universidades. O sea, hay mucha destrucción de lenguas, que están muriendo ahora. Hay un problema muy fuerte y tendremos que enfrentar eso. En Ecuador había una tradición linda de educación bilingüe y pienso que eso sería interesante, pero tienen que ser las comunidades indígenas las que lo controlen.

Tristán: Para terminar, entonces, una breve reflexión de cada uno sobre el futuro, el pronóstico para los próximos años y qué hace falta para avanzar con este proyecto de transformación, de construcción de la ecología de saberes dentro de las universidades.

Luis Fernando: Yo quisiera reflexionar sobre dos cosas a propósito lo que Tristán nos plantea. Lo primero es que buena parte del ejercicio de descolonización tiene que ver no con descolonizar a los pueblos indígenas, sino con descolonizar el campo académico, descolonizarnos quienes somos más convencionales. Buena parte de esa descolonización también tiene que ver con ser críticos con el desarrollo de las iniciativas. A veces, por una cuestión de apoyo, las nuevas iniciativas se convierten en un nuevo dogmatismo, cuando buena parte del ejercicio de descolonización se basa en la duda mientras planteamos la acción. Creo que es un momento útil, por decirlo de alguna manera, la crisis de 
la pandemia nos invita a repensar los contenidos, a repensar los medios y a repensar los fines, tanto en lo convencional, como en las iniciativas, y en ser críticos y autocríticos sobre ese tema. Creo que esa parte, que el mundo académico tiene el poder para hacerlo, creo que no se debe dejar de lado y no debemos dejarle esto al Estado porque corremos el riesgo de que se instrumentalice. Esa sería mi reflexión final.

Boaventura: Yo estoy de acuerdo con lo que dice Luis Fernando. Puedo añadir que es eso, la necesidad, como dice, es descolonizar el conocimiento académico en las instituciones porque, finalmente, en todas las universidades, desde el siglo XVI -incluso las que se crearon después, las que fueron creadas por los españoles en América Latina - la enseñanza era el conocimiento eurocéntrico, nunca entró el conocimiento indígena. Y es por eso que fueron tan colonizadoras del conocimiento, tanto fuera como dentro de Europa, lo que llamo las epistemologías del norte, están en un lado y están en el otro. Por eso, el norte y el sur para mí no es algo geográfico, es epistémico, porque hay sur epistémico en el norte y hay mucho norte epistémico en el sur. Gente que piensa que no hay más que la ciencia y las epistemologías del norte, que piensa que la filosofía empezó con los griegos y nada de egipcios, nada de cultura islámica, persa, etcétera, que son las raíces de la diversidad de los conocimientos. Entonces me parece que eso es necesario.

Ahora, para mí, el gran reto es que la educación refleja en cada momento la sociedad en la que está y los movimientos que están en la sociedad. Estamos, a mi juicio, en un momento de desemancipación, un momento de retroceso histórico. De alguna manera, el crecimiento de la extrema derecha en Europa, en el mundo, es un poco la señal de este retroceso desemancipador. Y eso, obviamente, va a tener una repercusión en la educación. Es muy posible que lo que hicimos con dificultad hasta ahora sea todavía más difícil en el futuro, y sobre todo en este contexto de pandemia intermitente. Ustedes saben que, sobre todo en mi trabajo, como en el último libro El fin del imperio cognitivo, yo dejo eso muy claro, que no tiene sentido descolonizar la universidad como si el colonialismo fuera el único mal de nuestra sociedad. Nuestras sociedades son capitalistas, colonialistas y patriarcales; son tres los ejes de dominación y, por eso, para descolonizar yo necesito desmercantilizar la sociedad, despatriarcalizar la sociedad. Y tu ves que la violencia en contra de los jóvenes negros va en aumento, en todos lados. En Europa también tenemos violencia en contra de los inmigrantes, de los musulmanes. Violencia en contra de las mujeres va en aumento. El capitalismo cada vez más agresivo para la naturaleza y para los obreros. Cada vez mas, todo este trabajo, teletrabajo, precario tiene cada vez menos derechos. Hay un retroceso histórico. Yo sigo, obviamente, como un intelectual del público y de retaguardia, nunca desisto y soy un optimista trágico, o sea, sigo pensando que hay esperanza, pero las dificultades son enormes porque esta pandemia... Mira, por ejemplo, las calles. Pienso que si nosotros queremos crear un movimiento descolonizador los estudiantes tienen que reunirse en los campus de la universidad, la gente tiene que protestar en las calles. ¿Quién está protestando en las calles hoy, en el mundo? 
La extrema derecha, la gente de derecha en algunos países, mira los Estados Unidos, mira Brasil. Los de izquierda tienen miedo a la pandemia, al virus. La extrema derecha, porque es una clase más alta muchas veces, parece no tener miedo. Un poco loco, pero es así.

Pienso que vamos a entrar en un proceso donde la protesta social puede ser brutalmente reprimida y por eso las conquistas sociales pueden ser derrotadas y todos estos años que tuvimos pueden perderse, aunque nunca de manera definitiva. Por eso vamos a tener que hacer lo que llamo la sociología de las emergencias, o sea, todo lo que en nuestros países emerge como interesante, novedoso, lo que llamo muchas veces las ruinas-semillas. Son cosas que estaban en ruinas y que de repente tú ves una semilla que surge, en esta comunidad, una universidad, una iniciativa educativa, ... debemos ampliarla, debemos darla a conocer. Es la responsabilidad de los educadores comprometidos con una sociedad más justa.

Recibido el 10 de septiembre de 2021 Aprobado el 19 de octubre de 2021

\section{Referencia}

ALICE-ES. Programa de Investigación Alice - epistemologías del Sur. Coimbra: Centro de Estudos Sociais; Colégio de S. Jerónimo, 2020. Disponible en: https:// alice.ces.uc.pt/en/index.php/upms/?lang=pt. Acceso en: 11 abr. 2021.

Boaventura de Sousa Santos es Catedrático de Sociología de la Facultad de Economía de la Universidad de Coimbra y Distinguished Legal Scholar en la Facultad de Derecho de la Universidad de Wisconsin-Madison. Además, es Director Emérito del Centro de Estudios Sociales de la Universidad de Coimbra. Ha publicado extensamente sobre epistemología, sociología del derecho, sociología política, teoría postcolonial, globalización, movimientos sociales, democracia multicultural y derechos humanos, en portugués, español, inglés, italiano, francés, alemán, chinés y rumano.

ORCID: https://orcid.org/0000-0003-3359-3626

E-mail: bsantos@ces.uc.pt

Luis Fernando Cuji Llugna es Subsecretario de Instituciones de Educación Superior de la Secretaría de Educación Superior, Ciencia, Tecnología e Innovación (Senescyt - Ecuador). Estudia políticas públicas en educación superior, calidad en educación superior e, interculturalidad. Tiene estudios en filosofía de la ciencia en la Universidad Nacional Autónoma de México. ORCID: https://orcid.org/0000-0002-1283-1667

E-mail: lfcuji@gmail.com

Editor-responsável: Luís Armando Gandin

Este é um artigo de acesso aberto distribuído sob os termos de uma Licença Creative Commons Atribuição 4.0 Internacional. Disponível em: <http:// creativecommons.org/licenses/by/4.0>. 